\title{
In Vitro and Enzymatic Studies of Inhibitory Activities of Three Trichoderma Species against Pythium Aphanidermatum in Infected Sweet Pepper
}

\author{
Salami, Abiodun Olusola1; Oni, Ayodeji Christopher'; Idowu, \\ Oluyemi Olawumi ${ }^{1}$
}

${ }^{1}$ Crop Production and Protection Department, Obafemi Awolowo University, Ile- Ife. Osun State. Nigeria

\begin{abstract}
This study investigated the antifungal activities of Trichoderma species against Pythium aphanidermatum; determined and measured the induction of defense enzymes (such as peroxidase, polyphenol oxidase and phenylalanine ammonia lyase) by Trichoderma species in seedlings inoculated with Pythium aphanidermatum. This was with a view to obtaining the best antagonist among the Trichoderma species. Inhibition percentages of the three Trichoderma species on Pythium aphanidermatum were determined via dual inoculation method and via production of volatile compounds. Fifteen day old seedlings of treated and untreated seeds were inoculated with $5 \times 10^{5}$ spores/ ml of Pythium aphanidermatum. Extraction of enzymes was carried out at different time interval of 1, 3, 5, 7, 9 and 11 days after pathogenic inoculation and they were assayed. The phenolic content for each of the treatment was also determined. The in vitro results suggested that, Trichoderma harzianum and T. koningii inhibited the growth of Pythium aphanidermatum mainly through their higher competitive abilities for space (on the plate) and nutrients at the expense of $P$. aphanidermatum, while $T$. atroviride inhibited the growth of $P$. aphanidermatum on the third day before occupying the space and absorbing nutrients from the substrates. The peroxidase activities were higher in T. atroviride plus pathogen in comparison with its activities in $T$. atroviride alone, T. harzianum alone and pathogen alone, while higher accumulation of phenolic contents was recorded in dual inoculations with T. atroviride than with T. harzianum. The study confirmed the ability of $T$. atroviride to inhibit the infection of $P$. aphanidermatum through the induction of activities of oxidative enzymes, competition and mycoparasitism, which was found to be high in interactions with the pathogen at all levels.
\end{abstract}

Keywords: Trichoderma harzianum, Trichoderma atroviride, Trichoderma koningii, Pythium aphanidermatum, Inhibition percentages and Induction of defense enzymes.

\begin{abstract}
Introduction
Trichoderma species are effective in controlling various diseases caused by soil-borne plant pathogenic fungi under greenhouse and field conditions (Morsy et al. 2009). Trichoderma species adopted many complex mechanisms of action which involve myco-parasitism, competition for nutrients, antibiosis, space competition and production of cell wall degrading enzymes (Verma et al., 2007). The antagonistic nature of Trichoderma may be due to its better nutrient utilization and space competition, hyperparasitism, and production of cell wall degrading enzymes. Additionally, Harman (2006) stated that Trichoderma species utilize various mechanisms, namely; inhibition of pathogen, initiation of plant enzymes, aid in the processes of biodegradation, carbon and nitrogen cycling and
\end{abstract}

complex interactions with plant roots in the rhizosphere. The various processes such as colonization, plant growth stimulation, bio-control of diverse plant pathogens, and decomposition of organic matter, symbiosis, and nutrient exchange are also involved in root-Trichoderma interaction.

\begin{abstract}
They secreted variety of volatile and non-volatile compounds with antibiotic properties (Ajith and Lakshmidevi, 2010). Large varieties of volatile secondary metabolites produced by Trichoderma such as ethylene, hydrogen cyanide, aldehydes and ketones play an important role in controlling the plant pathogens (Vey et al., 2001). Trichoderma species are able to antagonise other fungi by a variety of active and passive mechanisms. The passive mechanism would be
\end{abstract}


the organism's ability to dominate substrates through its fast growth rate, rapid spore production, metabolic versatility and tolerance of environmental stresses particularly chemicals.

Antifungal compounds produced by Trichoderma are effective against a wide range of fungal phytopathogens , namely; Fusarium oxysporum, Rhizoctonia solani, Curvularia lunata, Bipolaris sorokiniana and Colletotrichum species (Svetlana et al., 2010). Products from Trichoderma species are known to control numerous soil-borne diseases such as those caused by Fusarium oxysporum, Pythium species and Sclerotinia species.

Plant colonization by Trichoderma species reduced diseases caused by one or more different pathogens, at the site of inoculation (induced localized acquired resistance, LAR), also when the bio-control fungus was inoculated at different times or sites than that of the pathogen; age or time mediated application (induced systemic resistance, ISR). Naturally, plant enzymes are involved in defense reactions against invading pathogens. These include oxidative enzymes such as superoxide dismutase, peroxidase, catalase and polyphenol oxidase, which catalyse the formation of lignin and other oxidative phenols that contribute to the formation of physical or biochemical defence barriers for reinforcing the cell structure (Avdiushko et al., 1993). Harman et al. (2004) reported that the induction of plant defense responses mediated by the antagonistic fungus has been well documented. Many monocotyledonous and dicotyledonous plants have shown increased resistance to pathogen attack when treated with Trichoderma species. Specific strains of fungi in the genus Trichoderma colonize and penetrate plant root tissues and initiate a series of morphological and biochemical changes in the plant, considered to be part of the plant defense response, which subsequently leads to induced systemic resistance. The induction of systemic resistance in host plant following treatment with Trichoderma species was supported by the work of Yedidia et al. (1999), who demonstrated that inoculating roots of 7-day-old cucumber seedlings in an aseptic hydroponic system with $T$. harzianum, causes plant defense responses in both the roots and leaves of treated plants. They also demonstrated that hyphae of the bio-control fungus penetrated the epidermis and upper cortex of the cucumber root. Induced disease resistance is an active plant defense process that depends on physical or chemical barriers in the host and is activated by biotic or abiotic inducing agents (Thomashow, 1996).

This induction of resistance in plants has been reported to correlate with an increased in activities of peroxidase and polyphenol oxidase, which retarded disease development through the formation of polymerized phenolic barriers around the infection sites (Li and Steffens, 2002). The higher levels of these plant enzymes namely; phenylalanine ammonia lyase, peroxidase and chitinase were observed, and correlated with an increased resistance to artificial infection. It has been reported that ISR mediated by antagonists or bio-control agents against Pythium aphanidermatum in cucumber was associated with an increase of peroxidase, polyphenol oxidase and phenylalanine ammonia lyase activities, which enhance resistance in plants against the pathogen. Metabolic changes involved in the defense mechanism of plants are found to correspond with changes in activities of key enzymes implicated in primary and secondary metabolisms.

The peroxidase activity increases in plants during pathogen infection and has been correlated with resistance. The increase of peroxidases after infection or elicitation often correlates with the appearance of new isoforms of the enzymes (Chittoor et al., 1997). The roles in defense include oxidation of hydroxycinnamyl alcohols into free radical intermediates, oxidation of phenols, cross-linking of polysaccharides and of extensin monomers, lignification and suberization. Some forms can also generate active oxygen species as part of the oxidative burst during incompatible interactions (Hiraga et al., 2001). Polyphenol oxidase has been implicated as functioning in the defense mechanism against insects and plant pathogens (Das et al., 2004). Li and Steffens (2002) suggested several possibilities through which polyphenol oxidase inhibits growth of pathogens, these are (a) general toxicity of PPO-generated quinones to pathogens and plant cells, accelerating cell death, (b) alkylation and reduced bioavailability of cellular proteins to the pathogen, (c) cross-linking of quinones with protein or other phenolic contents, forming a physical barrier to pathogens in the cell wall, and (d) quinone redox cycling leading to generation of $\mathrm{H}_{2} \mathrm{O}_{2}$ and other reactive oxygen species. PPO is implicated in the formation of melanin-like polymers in potato black spot lesions (Stevens et al., 1998).

Trans-cinnamic acid, which was the result of activity of phenylalanine ammonia lyase in propanoid pathway, is involved in biosynthesis of lignin. Additionally, linked pathways, as a result of involvement of PAL, lead to the synthesis of compounds that have diverse functions in plants, notably in defense, such as cell wall strengthening and repair (e.g. lignin and suberin), antimicrobial activity (e.g. furano-coumarin, pterocarpan and isoflavonoid phytoalexins), and as signalling compounds such as salicylic acid (Hammerschmidt, 1999).

Phenols have been known to occur in all plants (Doka et al., 2004). Some of them occur constitutively, 

in Infected Sweet Pepper

whereas others are formed in response to pathogen invasion and are associated as part of active defence response in the host plant (Nicholson and Hammerschmidt, 1992). The constitutive phenolics are known to confer resistance either directly or indirectly through activation of post-infection responses in the host plants.

Trichoderma treatment also initiated greater production of defense enzymes and sustains their activities for a longer period in a pathogen-plant interaction. This was expressed in Trichoderma asperellum treated tomato seedlings challenged with Ralstonia solanacearum causing bacterial wilt of tomato. It was found to induce resistance into tomato plant against $R$. solanacearum pathogen. However, the capacities of these enzymes to induce resistance have not been sufficiently investigated in crops infected by root pathogens. Hence this study was sets out to investigate the production of these enzymes in $P$. aphanidermatum infected sweet pepper as induced by three species of Trichoderma.

Therefore the objectives of this study were to investigate the antifungal activities of Trichoderma species against Pythium aphanidermatum; and determine and measure the level of induction of defense enzymes such as peroxidase, polyphenol oxidase, phenylalanine ammonia lyase by Trichoderma species in seedlings inoculated with Pythium aphanidermatum.

\section{Materials and methods \\ Collection and identification of experimental materials}

Sweet pepper (California wonder) seed was obtained from a subsidiary of Premier Seed Company in Ibadan. The mycelium of $P$. aphanidermatum was taken from infected tomato seedlings showing the symptom of damping-off disease at the Teaching and Research Farm, Obafemi Awolowo University (O.A.U). The spores of the three Trichoderma species used for this study were collected from rotten root residue and soil compost around the screen-house of Faculty of Agriculture, O.A.U and were identified using standard protocol by Watanabe, (2002).

In vitro inhibition assay by dual culture method. Interaction between Trichoderma spp and Pythium aphanidermatum was determined by the method of Salami et al., (2011). A $5 \mathrm{~mm}$ diameter mycelial disc from the margin of seven old Trichoderma species culture and Pythium aphanidermatum was placed on the opposite side of the plate at equal distance from the periphery $(3 \mathrm{~cm}$ apart). While sterile agar disc was plated in control, instead of Trichoderma spp at opposite side of the pathogen Pythium aphanidermatum inoculated disc. Experimental layout was complete randomized design (CRD). Incubation was done at $28 \pm 2{ }^{\circ} \mathrm{C}$ and observed after 3 days, while the radial growth of the pathogen was taken for 7 consecutive days. The colony interaction was calculated as percentage inhibition of the radial growth by the following formula (Mishra, 2010)

$=(\mathrm{R} 1-\mathrm{R} 2) / \mathrm{R} 1 \times 100$, Where: $\mathrm{R} 1$ denotes diameter of the radial growth of the pathogen towards opposite side; and R2 denotes the radial growth of the pathogen towards the opponent antagonist.

\section{In vitro inhibition assay via production of volatile compounds.}

Inhibition due to productions of volatile compounds by the three Trichoderma spp on $P$. aphanidermatum were determined as described by Goyal et al. (1994). Three (3) mm disc of three days old cultures of each of the 3 Trichoderma isolates used for this study was centrally placed on different PDA plates and incubated at $28 \pm$ $2^{\circ} \mathrm{C}$ for three days. The cover of each petri-dish containing Trichoderma species was replaced with PDA plate of $P$. aphanidermatum. Petri-dish of PDA medium without Trichoderma spp was maintained as control. The pair of each petri-dish was sealed together with paraffin tape and incubated. Readings of the growth rate of the pathogen was taken from day 1 to day 5 of incubation with CRD experimental layout. After which the inhibition of mycelial growth of the pathogen was calculated using formula by Mishra, (2010).

\section{Treatment of pepper seeds with Trichoderma} species for in vivo studies.

The spores concentration of each Trichoderma species were standardized through serial dilution to $2.5 \times 10^{6}$ conidia/ml using haemocytometer, $25 \mathrm{~g}$ of pepper seeds were soaked in $100 \mathrm{ml}$ of the suspension for 2 hours, after which they were air-dried overnight. Seeds for the control were soaked in sterile water and were sown immediately in an experimental pot filled with sterilized soil.

\section{Induction of defense mechanisms in seedlings and experimental design}

Fifteen day old seedlings of the treated and untreated seeds were inoculated with $10 \mathrm{ml}$ of suspension containing $5 \times 10^{5}$ spores $/ \mathrm{ml}$ of $P$. aphanidermatum. Seedlings raised from untreated seeds, Trichoderma spp treated seeds and Pythium spp challenged seedlings, were carefully uprooted at different time intervals namely; $1,3,5,7,9$, and 11days after the inoculation of pathogen for enzymes assay.

\section{Assays of crude oxidative enzymes}

For the enzyme assay, root of pepper plant sample was homogenized in the ratio of $1: 2 \mathrm{~g} / \mathrm{ml}$ with $50 \mathrm{mM}$ sodium phosphate buffer $(\mathrm{pH} 6.0)$ at $4^{\circ} \mathrm{C}$. The homogenate was centrifuged at $4,000 \mathrm{rpm}$ for 15 minutes. The supernatant was then used as a crude 

in Infected Sweet Pepper

extract for enzyme activity. Crude enzyme extract in 0.1 M sodium phosphate buffer ( $\mathrm{pH}$ 7.0) was used for the estimation of PER, PPO and PAL. Enzyme extract was stored in deep freezer $\left(-20^{\circ} \mathrm{C}\right)$ and utilized for further biochemical analysis.

\section{Polyphenol oxidase assay}

Polyphenol oxidase (PPO) activity was determined according to the procedure given by NarasimhaMurthy et al. (2013). The reaction mixture consisted of $1.5 \mathrm{ml}$ of $0.1 \mathrm{M}$ sodium phosphate butter $(\mathrm{pH} 7.0)$ and $200 \mu 1$ of the enzyme extract. To start the reaction, $200 \mu 1$ of $0.01 \mathrm{M}$ catechol was added and enzyme activity was expressed as change in absorbance at $495 \mathrm{~nm} / \mathrm{min} / \mathrm{g}$ proteins.

\section{Peroxidase assay}

Peroxidase (PER) activity was carried out according to the procedure described by Reddy et al. (1995). To $3.0 \mathrm{ml}$ of pyrogallol solution, $0.1 \mathrm{ml}$ of the enzyme extract was added and adjusted to read zero with spectrophotometer at $430 \mathrm{~nm}$. Then, $0.5 \mathrm{ml}$ of $\mathrm{H}_{2} \mathrm{O}_{2}$ was added and mixed. The change in absorbance was recorded every 30 seconds for 3 minutes. One unit of peroxidase is defined as the change in absorbance/minute at $430 \mathrm{~nm}$. The enzyme activity was expressed as changes in the O.D. $\mathrm{min} / \mathrm{g} /$ protein.

\section{Phenylalanine ammonia lyase assay}

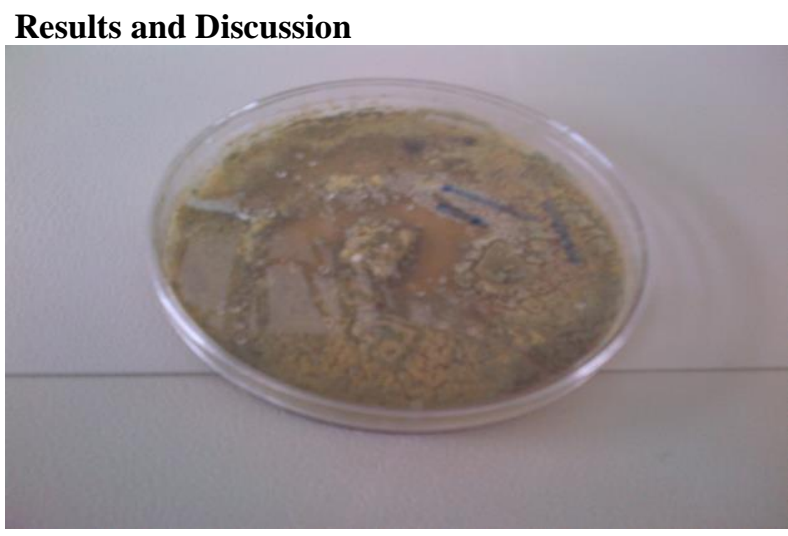

(a) Trichoderma koningii

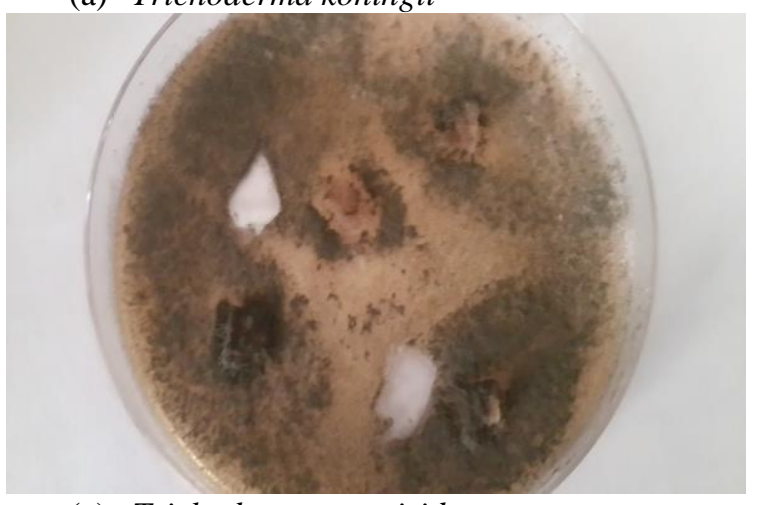

(c) Trichoderma atroviride
PAL activity was assayed by a modified form of a procedure of Narasimha-Murthy et al. (2013). The reaction mixture contained $1 \mathrm{ml}$ enzyme extract, $0.5 \mathrm{ml}$ substrate, $50 \mathrm{mM}$ L-phenylalanine and $0.4 \mathrm{ml} 25 \mathrm{mM}$ Tris-HC1 buffer ( $\mathrm{pH} 8.8$ ). After incubation for $2 \mathrm{~h}$ at $40^{\circ} \mathrm{C}$, the activity was stopped by the addition of 0.06 $\mathrm{ml} 5 \mathrm{~N} \mathrm{HC1}$ and the absorbance was read at $290 \mathrm{~nm}$ against the same volume of reaction mixture without Lphenylalanine that served as blank. The enzyme activity was expressed as trans-cinnamic acid /g protein.

\subsection{Estimation of total phenols:}

One gram of plant sample was homogenized in $10 \mathrm{ml}$ of $80 \%(\mathrm{v} / \mathrm{v})$ methanol and agitated for $15 \mathrm{~min}$ at $70^{\circ} \mathrm{C}$ (Zieslin and Ben-Zaken, 1993). One $\mathrm{ml}$ of the methanolic extract was added to $5 \mathrm{ml}$ of distilled water and $250 \mu \mathrm{l}$ of Folin-Ceocalteau reagent $(1 \mathrm{~N})$ and the solution was kept at $25^{\circ} \mathrm{C}$. The absorbance was measured using a spectrophotometer at $725 \mathrm{~nm}$ while catechol was used as the standard. The amount of phenols was expressed as $\mu \mathrm{g}$ catechol $\mathrm{mg}^{-1}$.

\section{Statistical analysis}

Data collected were analysed using SAS 9.0. and Microsoft excel. Laboratory data were subjected to analysis of variance (ANOVA). Fischer's LSD at 5\% was used to test means comparison for significant effects of the treatments.

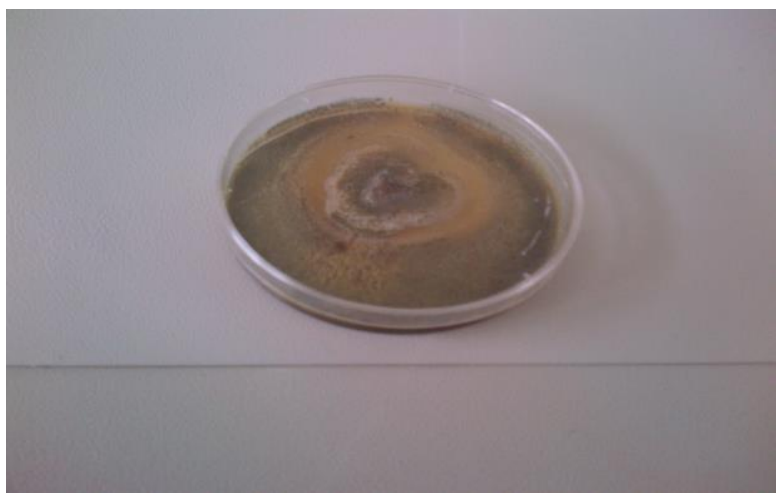

(b) Trichoderma harzianum

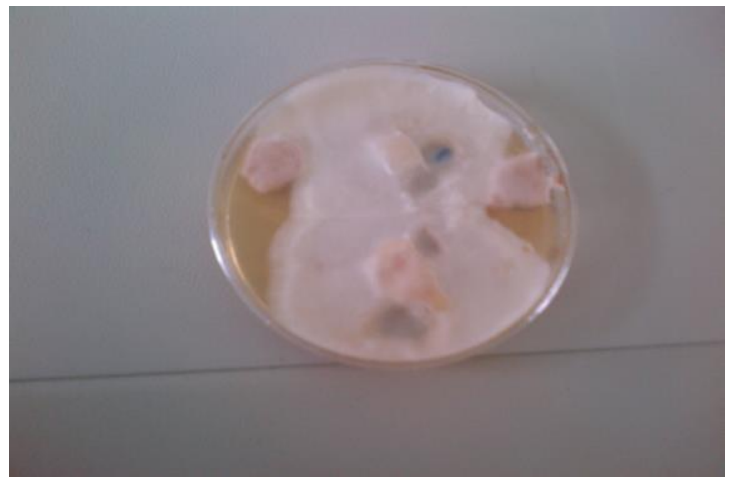

(d) Pythium aphanidermatum 


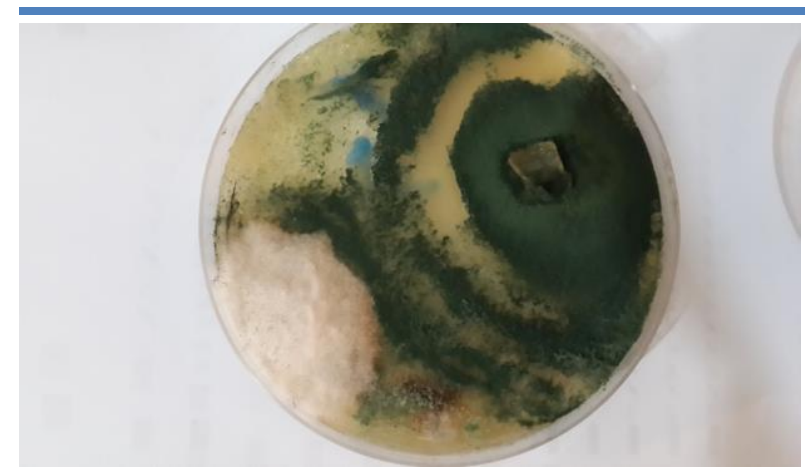

(e) Trichoderma atroviride with Pythium aphanidermatum on PDA.

Plate 2: Pictures of the three species of Trichoderma (a-c) and Pythium aphanidermatum (d).

Significant differences $(\mathrm{p}<0.01)$ were recorded for the mycelial inhibition of the test pathogen by three Trichoderma species used in this study, particularly for each day of interaction. In addition to this, inhibitory activities of volatile compounds produced by these three Trichoderma species indicated a significant effect on the growth of pathogen. The mean comparison of the percentage inhibitions (Table 1), indicated that for the first two days of measurement, both Trichoderma harzianum (62.9\% and 73.2\%) and Trichoderma koningii $(61.7 \%$ and $59.7 \%)$ had the equal inhibitory effects on Pythium aphanidermatum but higher than that of T. atroviride (29.3\% and $33.9 \%)$. On the 3rd day of measurement, only $T$. harzianum (70\%) recorded the highest percentage inhibition on $P$. aphanidermatum than in $T$. koningii accounting for $50.5 \%$, but not different from the percentage inhibition of $T$. atroviride $60.5 \%$, however both $T$. atroviride and $T$. koningii were of equal inhibitory effects. On the 4th day of measurement, only $T$. harzianum recorded $(77.1 \%)$ the highest inhibitory effects, when compared with the remaining two species, which were of the same effects. Moreover, from day 5 - day 7 of measurement, all the three Trichoderma species recorded equal inhibitory effects on the growth of $P$. aphanidermatum ranging from 64.6-79.6\%, these percentage inhibitions were significantly higher in effect than in the first two days, especially in $T$. atroviride. This suggested that higher inhibitory percentages were obtained for all the three Trichoderma species as the days of assay progresses and as from the 5th day of measurement all the three Trichoderma species exhibited the same inhibitory effects. It was also evident in Table 2; that T. atroviride $(13.2 \%)$ produced the highest inhibitory effect via production of volatile compounds on $P$. aphanidermatum, however, this was not different in inhibitory activities when compared with $T$. harzianum $(9.6 \%)$ but highly significant than that of $T$. koningii (5.4\%). Comparatively, inhibition percentage of $T$. harzianum via production of volatile compounds was not different from $T$. koningii.
Direct parasitism of the pathogen through production of antimicrobial compounds; competition for space and nutrients; and also by producing enzymes that attack the cell components of the pathogens are the antagonistic activities of Trichoderma spp, as observed in this study, thus, describing the nature of Trichoderma species as opined by other researchers. The result shows their ability to withstand or outgrow the pathogen on culture media through the fast use of the available nutrients within the growth medium. Also, the inhibition observed was with some variations among the three of Trichoderma species used. It could be deduced from the study that, Trichoderma species, especially $T$. harzianum and $T$. koningii utilized more space and absorbed nutrients in the growth medium at a faster rate than the pathogen though at different levels between one another. Hence, their competitive abilities generally were found to be higher than that of the pathogen. It was also established in this study that the Trichoderma species used, antagonized or inhibited the pathogen growth and development through the production of volatile compounds. This was observed when $T$. atroviride which recorded highest inhibitory action through production of volatile compounds retarded the growth of $P$. aphanidermatum better than $T$. koningii, although there was no visible evidence that $T$. atroviride possesses higher competitive ability over the pathogen for the first two days of the dual assay. This suggested that the inhibitory ability of $T$. atroviride on the test pathogen was initially triggered by production of volatile compounds, before growing visibly on the medium, at the expense of $P$. aphanidermatum, while T. koningii inhibited the pathogen through combined effects of competitive ability for nutrients and space with the little inhibitory effect of the volatile compounds. According to Kullnig et al. (2000) and Brunner et al. (2003) the dual culture interaction and volatile components revealed that Trichoderma species caused appreciable inhibition of mycelia growth of Fusarium solani. Studies have shown that before mycelial interaction these fungi (Trichoderma spp with pathogen), there was presence of inhibition zone, 
In Vitro and Enzymatic Studies of Inhibitory Activities of Three Trichoderma Species against Pythium Aphanidermatum in Infected Sweet Pepper

thereby suggesting the secretion of some antibiotics by Trichoderma species (Shashidhara et al., 2008 and Kerkeni et al., 2007). It has also been reported that Trichoderma species produced substantial amounts of volatile compounds against pathogens (Padmodaya and
Reddy, 1996). The major advantage of antibiosis through the production of volatile compounds is that, these substances may diffuse through the soil pores to control the growth of pathogens without establishing any form of physical contact.

Table 1: Mean comparison of the percentage inhibitions for dual inoculation of the three Trichoderma species and Pythium aphanidermatum across the days of interaction.

\begin{tabular}{llllllll}
\hline Treatments & Day1 & Day2 & Day3 & Day4 & Day5 & Day6 & Day7 \\
\hline T1+P & 62.9 & 73.2 & 70.0 & 77.1 & 77.5 & 75.1 & 64.6 \\
T2+P & 61.7 & 59.7 & 50.5 & 52.9 & 72.0 & 70.9 & 70.7 \\
T3+P & 29.3 & 33.9 & 60.4 & 62.8 & 69.9 & 69.3 & 79.6 \\
PO & 0.0 & 0.0 & 0.0 & 0.0 & 0.0 & 0.0 & 0.0 \\
LSD 0.05 & 15.9 & 14.6 & 11.9 & 14.6 & 20.6 & 18.4 & 23.9 \\
\hline \hline
\end{tabular}

T1+P- Plate with Pathogen and T. harzianum

T2+P- Plate with Pathogen and T. koningii

T3+P- Plate with Pathogen and T. atroviride

PO- Plate with Pathogen and Sterile cultures

Day1- On the 3rd day of placement in the same plate.

Day2- On the 4th day of placement in the same plate

Day3- On the 5th day of placement in the same plate

Day4- On the 6th day of placement in the same plate

Day5- On the 7th day of placement in the same plate

Day6- On the 8th day of placement in the same plate

Day7- On the 9th day of placement in the same plate

LSD- Least Significant Difference at $\alpha=0.05$.

Table 2: Mean comparison for the inhibitions assay of volatile compounds produced by three Trichoderma species against Pythium aphanidermatum.

\begin{tabular}{ll}
\hline Treatment & Percentage Inhibition \\
\hline T1+P & 9.6 \\
T2+P & 5.4 \\
T3+P & 13.2 \\
PO & 0.0 \\
LSD 005 & 7.2 \\
\hline
\end{tabular}

T1+P- Plate of T. harzianum covered with $P$. aphanidermatum culture

T2+P- Plate of $T$. koningii covered with $P$. aphanidermatum culture

$\mathrm{T} 3+\mathrm{P}$ - Plate of $T$. atroviride covered with $P$. aphanidermatum culture

PO- Plate with Pathogen and Sterile cultures

LSD- Least Significant Difference at $\alpha=0.05$.

Enzymatic activities in pepper seedlings treated with three species of Trichoderma

The differences of coefficient of determination $\left(\mathrm{R}^{2}\right)$ in quadratic regression equations and linear regression equations accounted for $19.36-76.43 \%$ especially in $P$. aphanidermatum inoculated pepper seedlings. The rates of increase in peroxidase activities were not significantly different when compared pathogen infected seedlings with control; dual and singular inoculations of T. harzianum and T. koninigi. However, T. atroviride treated seedlings recorded level of increase in peroxidase activities in dual inoculation (0.30-1.43 $\Delta$ in peroxidase activities) higher than in its singular inoculation (-0.03-0.13 $\Delta$ in peroxidase activities), $T$. harzianum $(-0.10-0.23 \Delta$ in peroxidase activities) and pathogen alone (0.04-0.24 $\Delta$ in peroxidase activities). Additionally the rate of increase in peroxidase activities in each of the dual inoculations was observed to be higher than in control (-0.06-0.12). The equation curve revealed that, there was fall in level of peroxidase activities as the days of assay progressed in all the treatments. Moreover, the decrease in the rates of peroxidase activities at the later days of assay was more pronounced in $T$. atroviride plus pathogen (0.04-0.20 decrease in peroxidase activities) which decline faster than in $T$. atroviride alone (0.01decrease in peroxidase activities) and control (0.01decrease in peroxidase activities). While $T$. harzianum plus pathogen (0.02-0.15 decrease in peroxidase activities) also decline at faster rate than $T$. atroviride 
In Vitro and Enzymatic Studies of Inhibitory Activities of Three Trichoderma Species against Pythium Aphanidermatum in Infected Sweet Pepper

(0.01decrease in peroxidase activities) and control (0.01decrease in peroxidase activities). Table 3 .

The differences in $\left(\mathrm{R}^{2}\right)$ accounted for $(20-84 \%)$ between the linear and quadratic functions revealed that, the trend of polyphenol oxidase activities in sweet pepper seedlings was better explained by quadratic equations as the days of assay progresses, except in $T$. koningii plus pathogen. The initial rates of increase in polyphenol oxidase activities were not different for all the treatment combinations. However, the degrees of decrease varied eventually, with $T$. koningii plus pathogen (0.05-0.04) decreasing at slower rate than in its singular inoculation (0.06- 0.36) and T. atroviride alone

(0.06-0.32).

Table 3: Comparison of the peroxidase and polyphenol oxidase activities in Trichoderma treated and Pythium aphanidermatum inoculated sweet pepper seedlings.

\begin{tabular}{lllllll}
\hline Treatments & \multicolumn{2}{c}{ For Peroxidase activities } & \multicolumn{2}{c}{ For Polyphenol Oxidase activities } \\
\hline & B1 \pm 2SEM & B2 \pm 2SEM & $\begin{array}{l}\text { Differences } \\
\text { In Coefficients of } \\
\text { determination }\end{array}$ & B1 \pm 2SEM & B2 2SEM & $\begin{array}{l}\text { Differences } \\
\text { In Coefficients of } \\
\text { determination }\end{array}$ \\
\hline CON & $0.03 \pm 0.09$ & $0.000 \pm 0.012$ & 0.01 & $0.29 \pm 0.27$ & $-0.046 \pm 0.043$ & 67.91 \\
T1 & $0.06 \pm 0.17$ & $0.002 \pm 0.023$ & 0.09 & $0.28 \pm 0.30$ & $-0.040 \pm 0.050$ & 41.54 \\
T2 & $0.31 \pm 0.27$ & $-0.041 \pm 0.038$ & 55.08 & $1.26 \pm 0.93$ & $-0.210 \pm 0.151$ & 79.40 \\
T3 & $0.05 \pm 0.08$ & $0.001 \pm 0.011$ & 0.04 & $1.19 \pm 0.77$ & $-0.190 \pm 0.127$ & 78.14 \\
T1+P & $0.61 \pm 0.44$ & $-0.090 \pm 0.062$ & 72.80 & $0.72 \pm 0.85$ & $-0.090 \pm 0.139$ & 19.74 \\
T2+P & $0.83 \pm 0.63$ & $-0.114 \pm 0.088$ & 66.33 & $0.21 \pm 0.29$ & $-0.003 \pm 0.047$ & 0.03 \\
T3+P & $0.86 \pm 0.57$ & $-0.124 \pm 0.080$ & 76.43 & $0.60 \pm 0.36$ & $-0.099 \pm 0.059$ & 84.04 \\
PO & $0.14 \pm 0.10$ & $-0.015 \pm 0.014$ & 19.36 & $0.26 \pm 0.25$ & $-0.038 \pm 0.042$ & 52.14 \\
\hline
\end{tabular}

CON- Untreated Seedlings

T1- T. harzianum treated pepper seedlings

T2- T. koningii treated pepper seedlings

T3- $T$. atroviride treated pepper seedlings

$\mathrm{T} 1+\mathrm{P}-T$. harzianum treated pepper seedlings + Pathogen

$\mathrm{T} 2+\mathrm{P}-$ T. koningii treated pepper seedlings + Pathogen

$\mathrm{T} 3+\mathrm{P}-T$. atroviride treated pepper seedlings + Pathogen

PO-Pathogen Only 


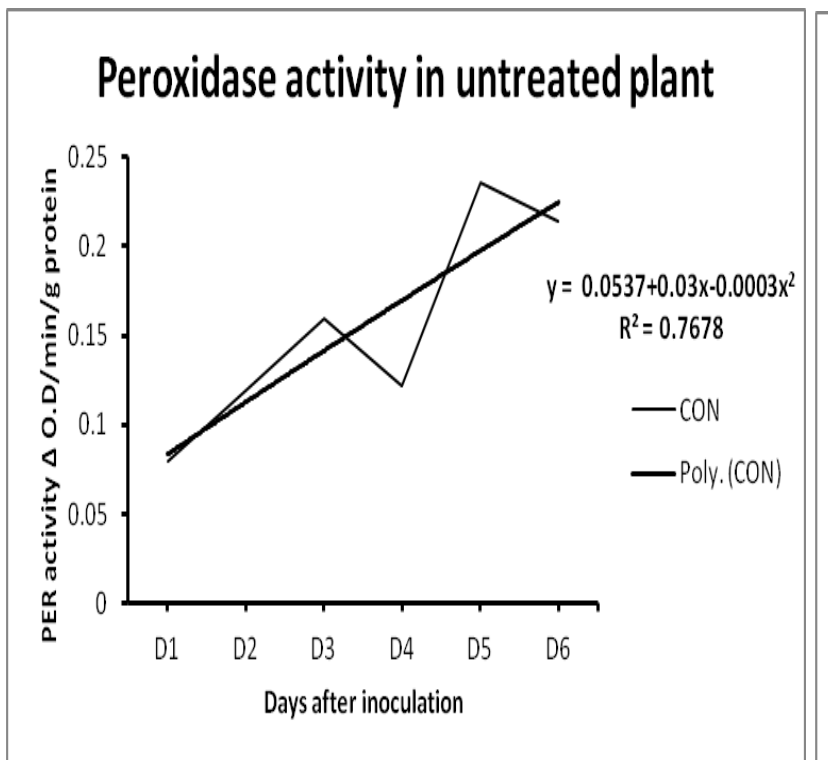

a. Untreated seedlings

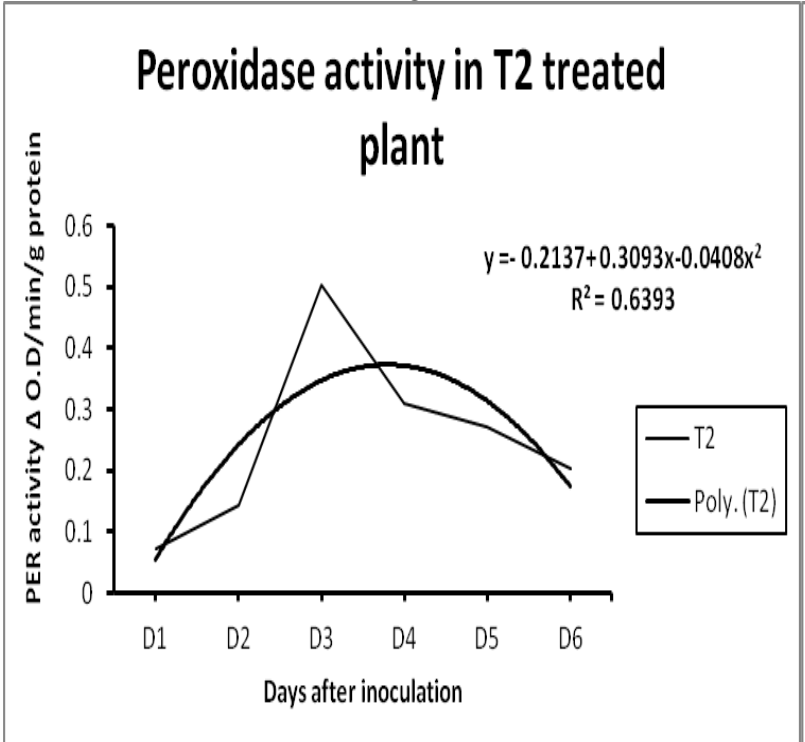

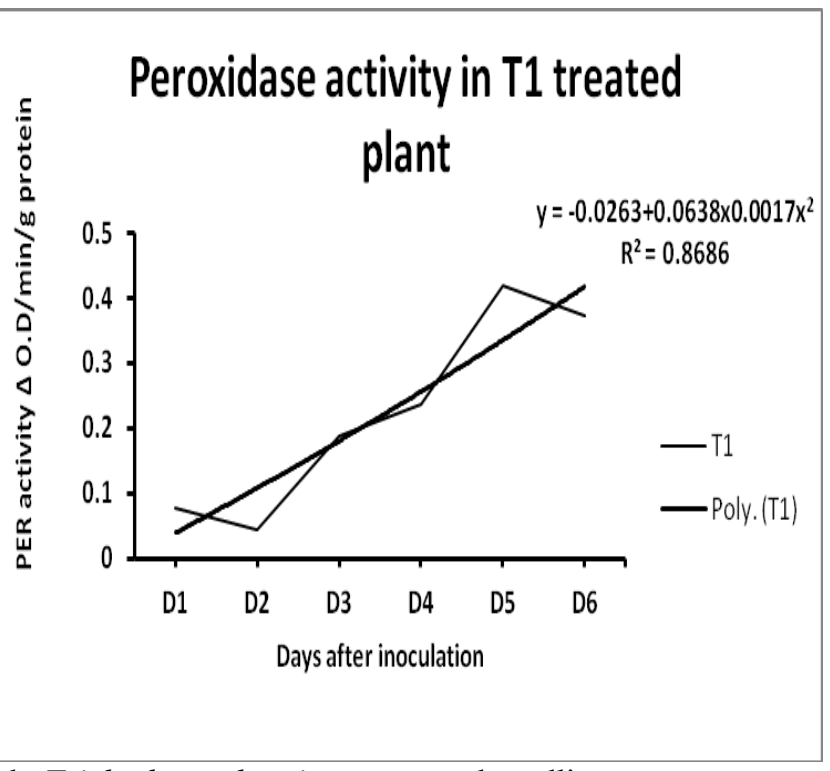

b. Trichoderma harzianum treated seedlings

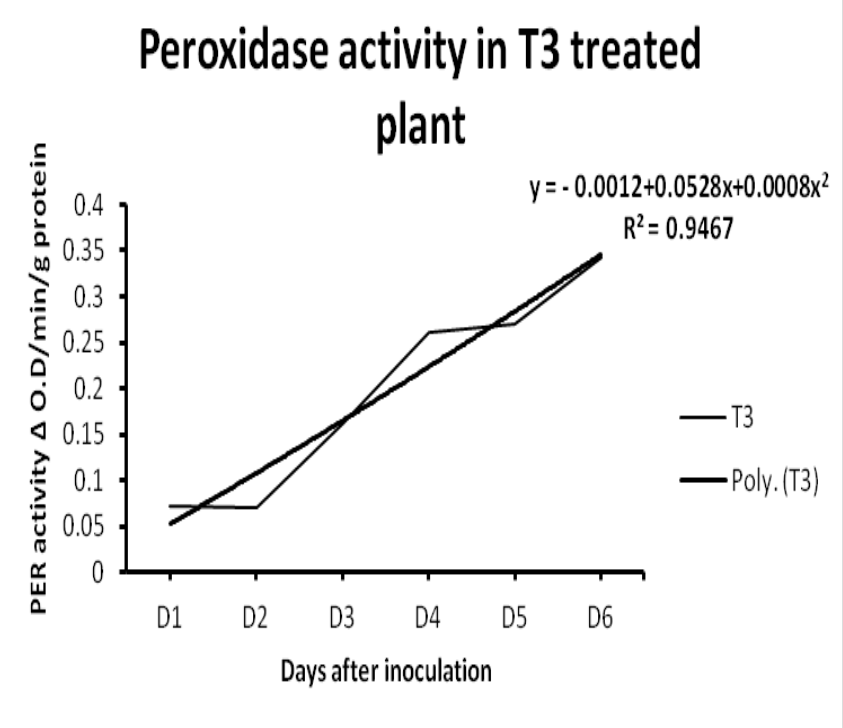

c. Trichoderma koningii treated seedlings d. Trichoderma atroviride treated seedlings

Figure 1: Changes in peroxidase activities of Trichoderma treated pepper (b-d) and untreated pepper (a) seedlings across the days of assay. 


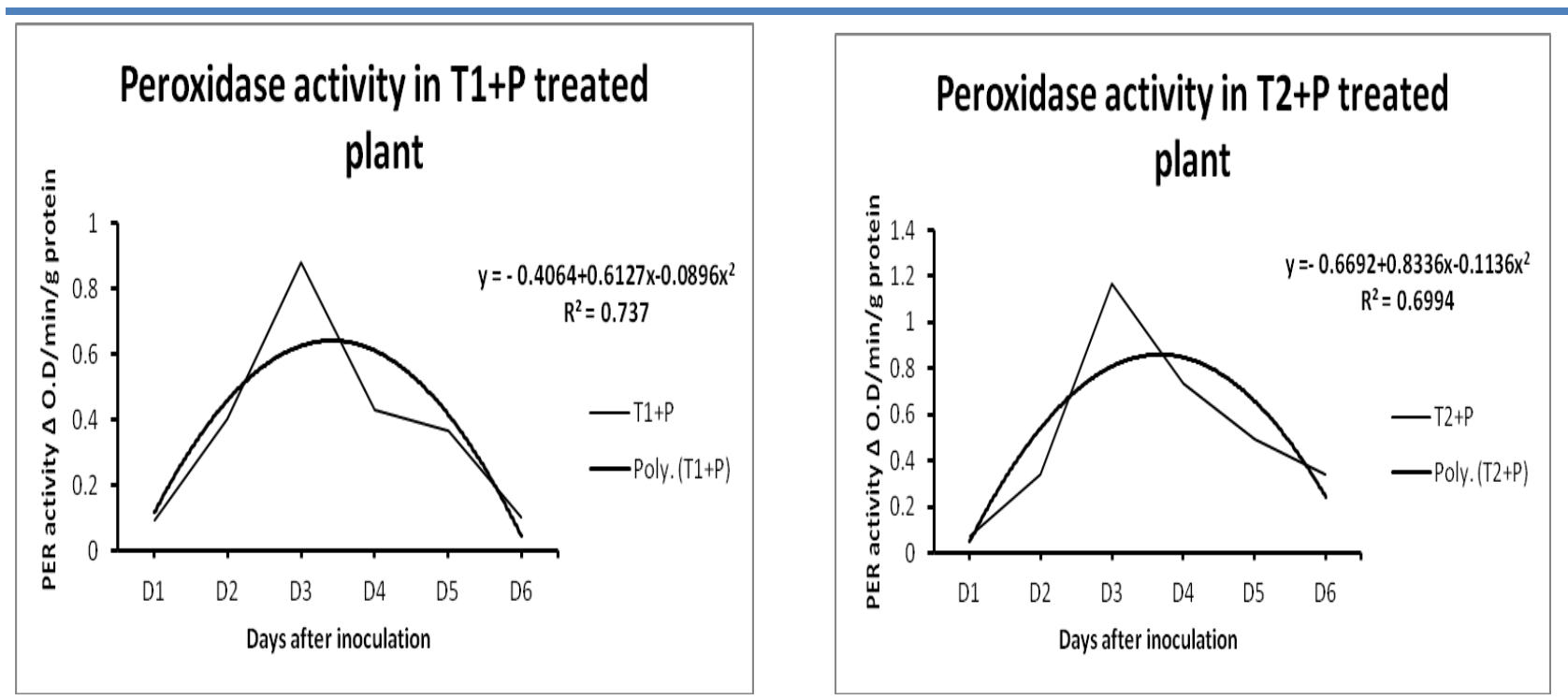

e. Trichoderma harzianum $+P$. aphanidermatum

f. Trichoderma koningii + P. aphanidermatum
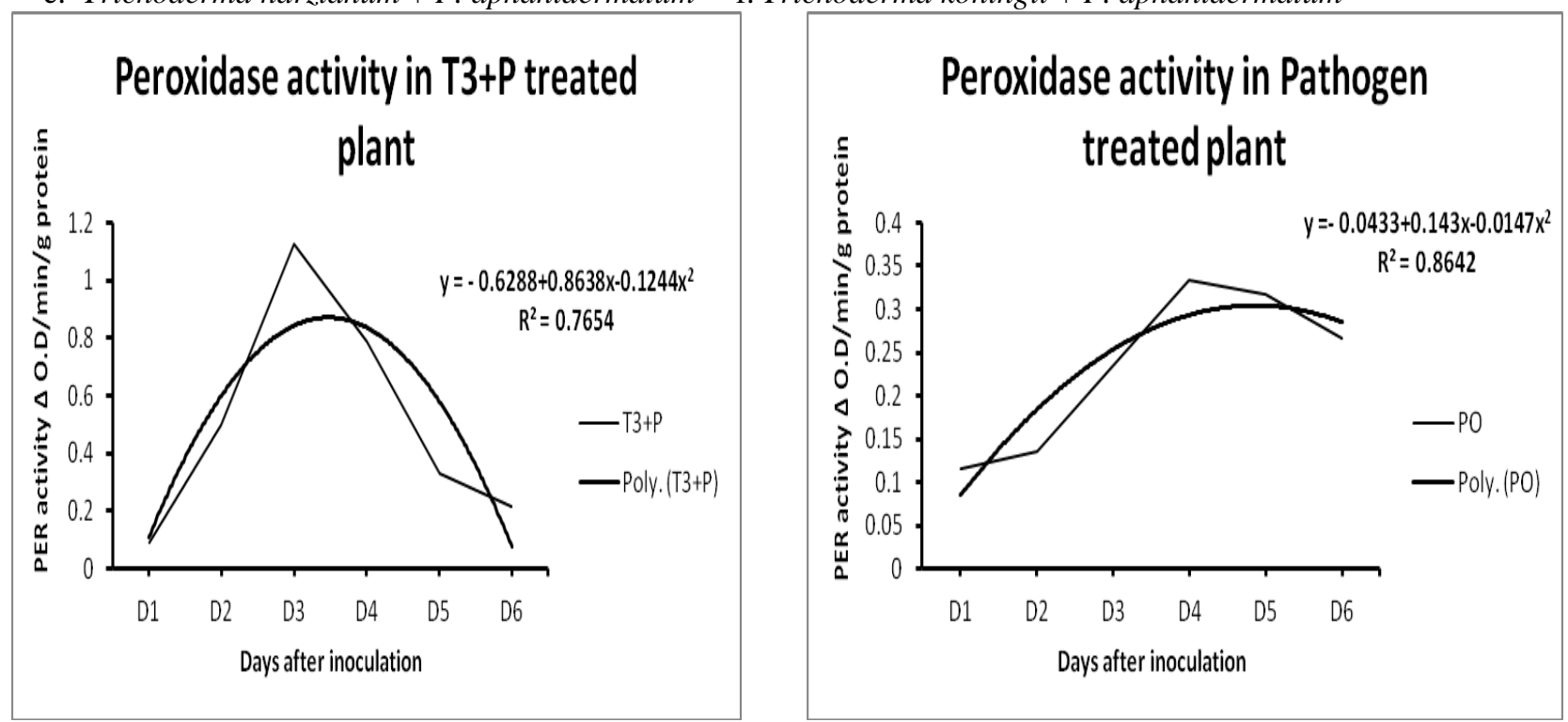

g. Trichoderma atroviride $+P$. aphanidermatum

h. P. aphanidermatum alone

Figure 2: Changes in peroxidase activities of Trichoderma treated pepper (e-g) and untreated pepper (h) seedlings inoculated by Pythium aphanidermatum across the days of assay.
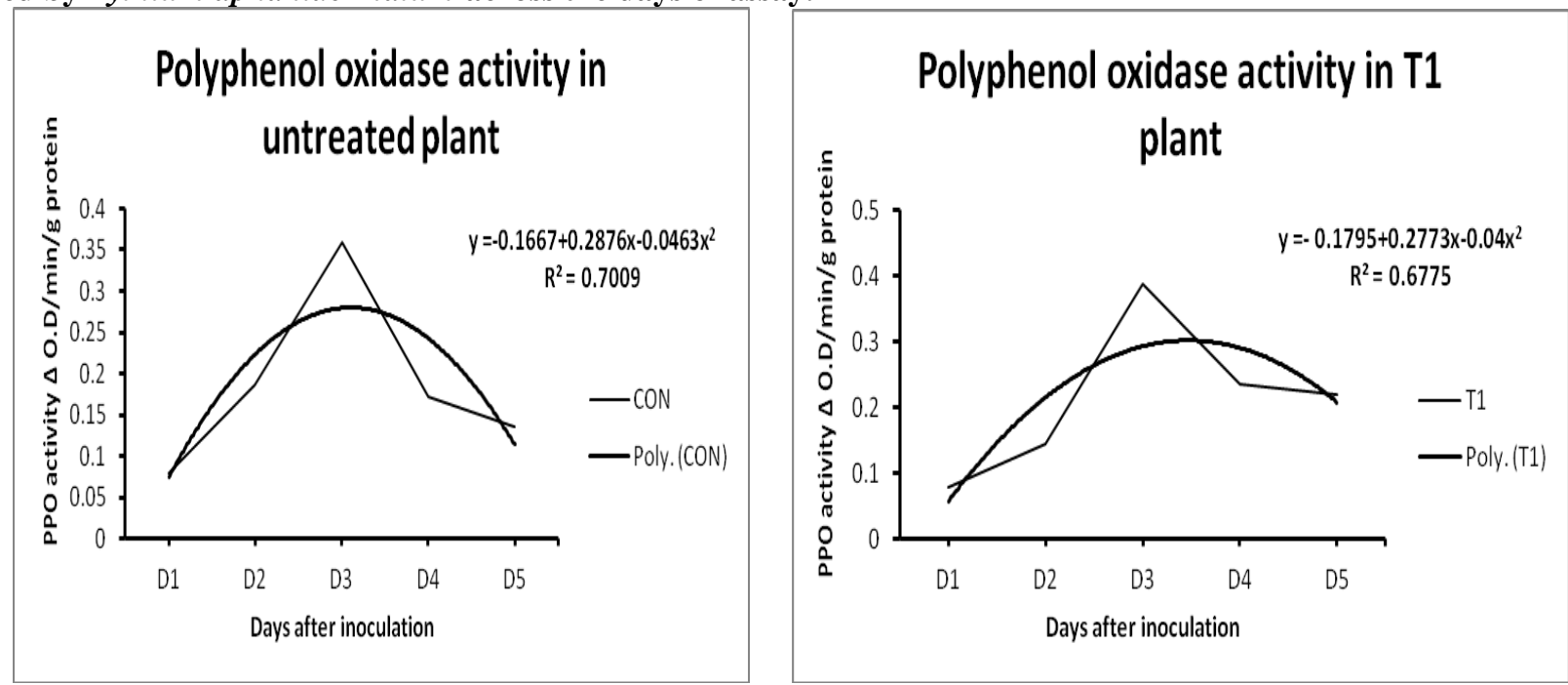
In Vitro and Enzymatic Studies of Inhibitory Activities of Three Trichoderma Species against Pythium Aphanidermatum in Infected Sweet Pepper

a. Untreated seedlings

Polyphenol oxidase activity in $\mathrm{T} 2$

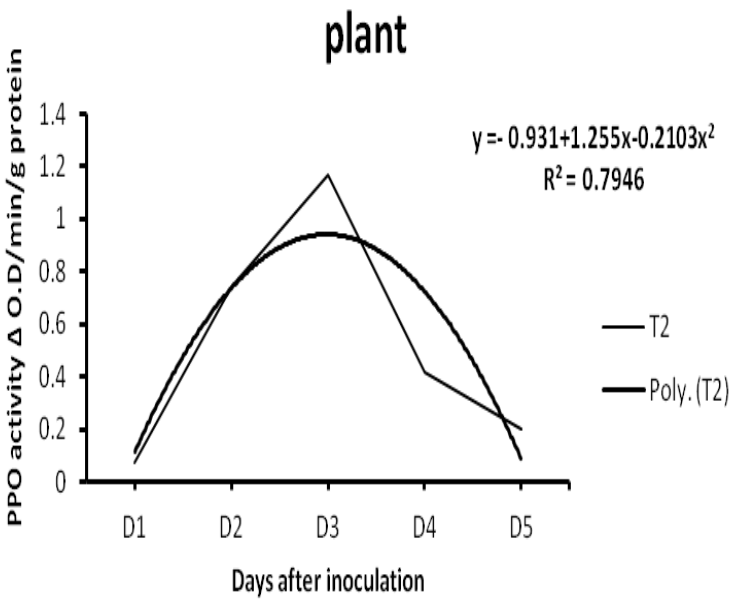

b. Trichoderma harzianum treated seedlings

Polyphenol oxidase activity in T3 plant

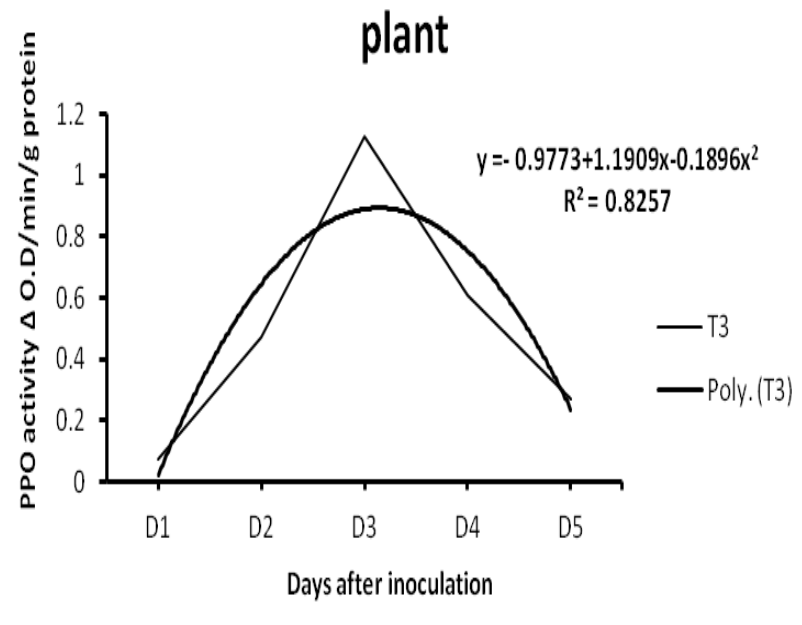

c. Trichoderma koningii treated seedlings d. Trichoderma atroviride treated seedlings

Figure 3: Changes in polyphenol oxidase activities of Trichoderma treated pepper (b-d) and untreated pepper (a) seedlings across the days of assay.

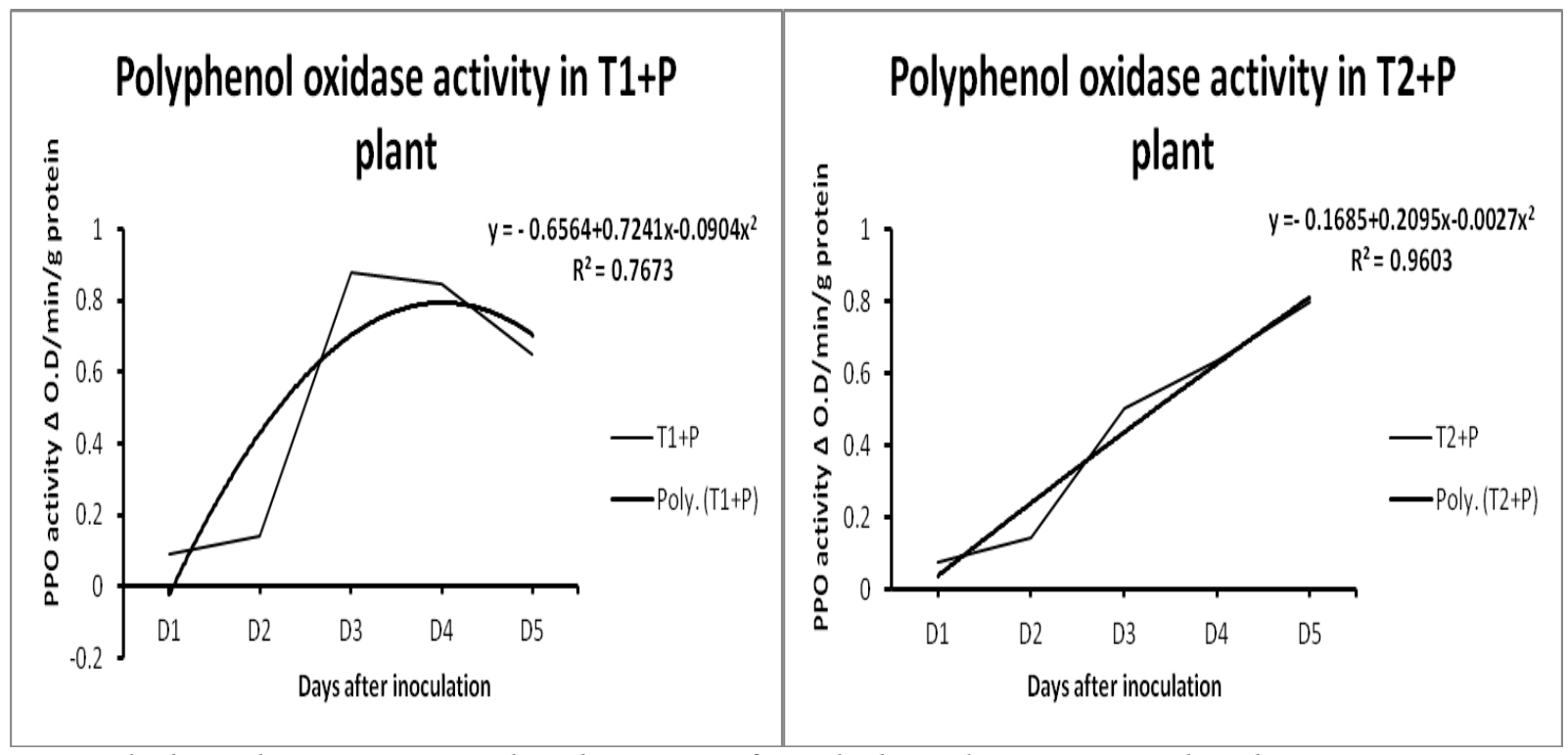

e. Trichoderma harzianum + P. aphanidermatum f. Trichoderma koningii + P. aphanidermatum 


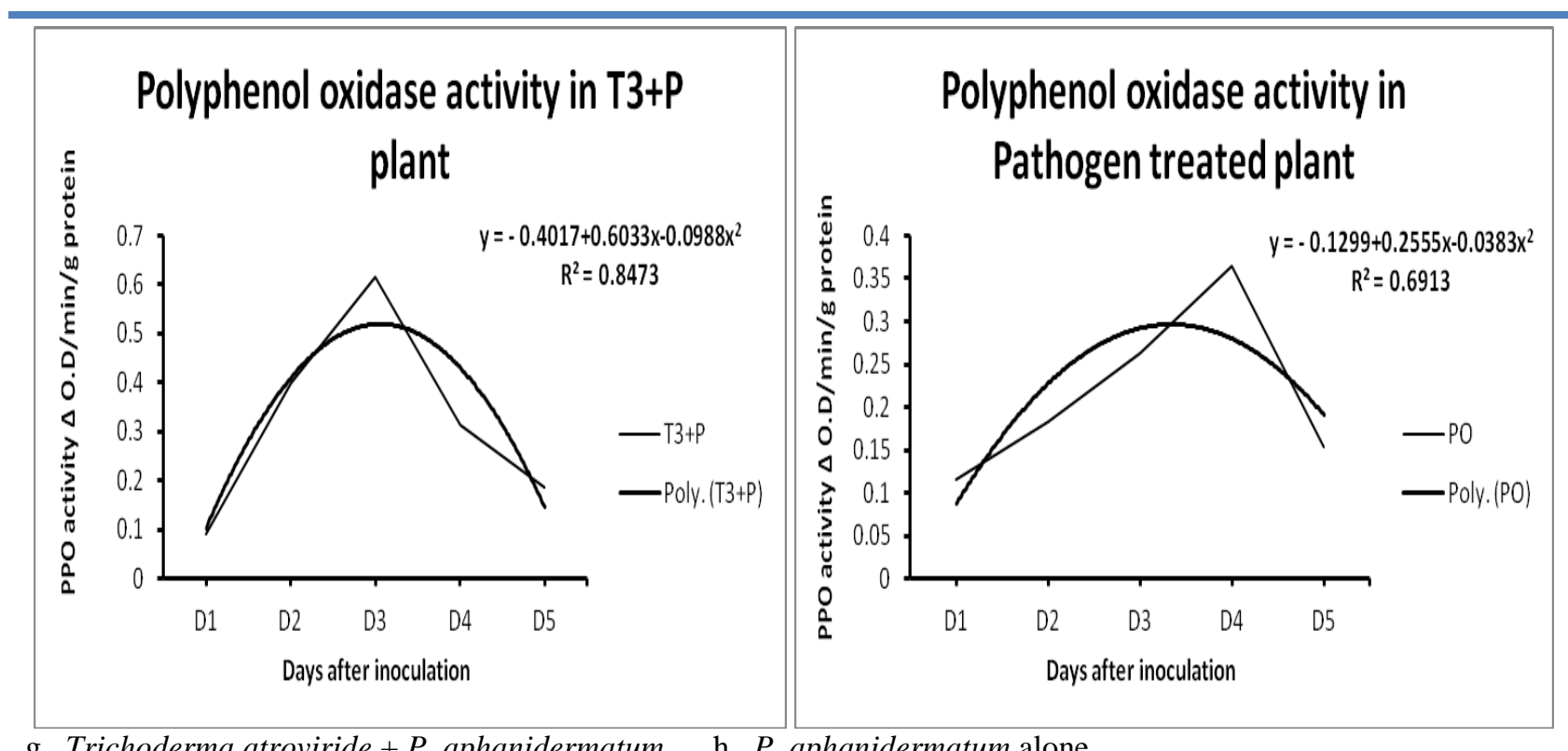

g. Trichoderma atroviride $+P$. aphanidermatum $\quad$ h. $P$. aphanidermatum alone

Figure 4: Changes in polyphenol oxidase activities of Trichoderma treated pepper (e-g) and untreated pepper (h) seedlings inoculated by Pythium aphanidermatum across the days of assay.

This trend was further explained in Fig. 3 and Fig. 4, that $69-96 \%$ variations in polyphenol oxidase activities were accounted for by the days of assays in quadratic functions. The initial levels of polyphenol oxidase activities were negative for all the treatments. The polyphenol oxidase activities tend to decrease at increasing rate throughout the days of assay in $T$ koningii plus pathogen, while there were sharp decreases in polyphenol oxidase activities within day 5 and day 9 in singular inoculations of $T$. koningii and $T$. atroviride.

Table 4 indicated that, the differences in $\mathrm{R}^{2}$ of both linear and quadratic functions ranged from 14-64.5\%, indicating that, the trend of phenylalanine ammonia lyase activities in sweet pepper seedlings was better explained by quadratic equations as the days of assay progresses for all the treatments. Additionally, the rates of initial decrease and of increase at the later days were not different for the effects of all the treatments. This trend was further explained in Fig. 5 and Fig. 6 that about $67-97 \%$ variations in phenylalanine ammonia lyase activities were accounted for by the days of assays in quadratic functions. The initial levels of phenylalanine ammonia lyase activities were positive for all the treatments.

The differences in $\mathrm{R}^{2}$ of linear and quadratic functions of phenolic contents were ranged between $10-70 \%$ for all other treatments, apart from $T$. koningii alone
(0.01). This indicates that changes in content of total phenols in sweet pepper seedlings were better explained by quadratic function (Table 8 ). The first order changes in the content of total phenols in all the treatments were at the same rates. However, a second degree rate of changes in phenolic contents was at increasing order in $T$. atroviride plus pathogen seedlings (9.84-73.6) when compared with $T$. harzianum plus pathogen seedlings which was decreasing at higher order of 10.15-62.15. From the graphs in Fig. 7 and Fig. 8; the initial amounts of total phenol in all the treatments were negligible except for the dual inoculation of $T$. atroviride and the pathogen which was positive. Also about $66-76 \%$ variations in phenolic contents were accounted for by the days of assays in quadratic functions. Many plant phenolic compounds are known to be antimicrobial, function as precursors to structural polymers such as lignin, or serve as signal molecules ( Hammerschmidt, 2005) .Significant increase in phenolic content was positively proportional to the degree of plant resistance against the pathogens (Abo-Elyousr et al.,2009). This was true for $T$. atroviride plus pathogen plants extract, whose phenolic contents increase gradually as from day 4 immediately after the inoculation of pathogen, to show that changes of post-infection process in phenol content to highly reactive species was more in the interaction between this antagonist and $P$. aphanidermatum. 
In Vitro and Enzymatic Studies of Inhibitory Activities of Three Trichoderma Species against Pythium Aphanidermatum in Infected Sweet Pepper

\begin{tabular}{lllllll}
\hline Treatments & \multicolumn{2}{l}{ For Phenylalanine Ammonia Lyase activities } & \multicolumn{2}{c}{ For Phenolic Contents } \\
& B1 2SEM & B2 2SEM & $\begin{array}{l}\text { Differences } \\
\text { In Coefficients } \\
\text { of determination }\end{array}$ & B1 2SEM & B2 2SEM & $\begin{array}{l}\text { Differences } \\
\text { In Coefficients } \\
\text { of determination }\end{array}$ \\
\hline CON & $-0.48 \pm 0.34$ & $0.056 \pm 0.047$ & 35.67 & $246.8 \pm 202.6$ & $-36.91 \pm 28.34$ & 67.20 \\
T1 & $-0.56 \pm 0.26$ & $0.068 \pm 0.036$ & 55.82 & $240.5 \pm 180.5$ & $-33.87 \pm 25.24$ & 70.35 \\
T2 & $-0.49 \pm 0.30$ & $0.056 \pm 0.042$ & 33.74 & $37.4 \pm 112.5$ & $-0.23 \pm 15.73$ & 0.01 \\
T3 & $-0.43 \pm 0.39$ & $0.047 \pm 0.055$ & 22.94 & $150.7 \pm 137.0$ & $-17.50 \pm 19.16$ & 32.09 \\
T1+P & $-0.60 \pm 0.14$ & $0.075 \pm 0.019$ & 64.45 & $240.3 \pm 186.0$ & $-36.15 \pm 26.00$ & 69.11 \\
T2+P & $-0.34 \pm 0.44$ & $0.034 \pm 0.061$ & 14.07 & $174.8 \pm 251.0$ & $-16.79 \pm 35.12$ & 10.27 \\
T3+P & $-0.42 \pm 0.35$ & $0.045 \pm 0.050$ & 21.86 & $-151.1 \pm 298.4$ & $31.88 \pm 41.72$ & 21.38 \\
PO & $-0.50 \pm 0.32$ & $0.057 \pm 0.044$ & 33.51 & $124.9 \pm 141.6$ & $-14.16 \pm 19.80$ & 24.87 \\
\hline
\end{tabular}

Table 4: Comparison of the phenylalanine ammonia lyase activies and the phenolic contents among the Trichoderma treated and Pythium aphanidermatum inoculated sweet pepper seedlings.

CON- Untreated Seedlings

Pathogen

T1- T. harzianum treated pepper seedlings

T2- T. koningii treated pepper seedlings

T3- T. atroviride treated pepper seedlings

$\mathrm{T} 1+\mathrm{P}-T$. harzianum treated pepper seedlings + Pathogen

$\mathrm{T} 2+\mathrm{P}-T$. koningii treated pepper seedlings + Pathogen
T3+P- T. atroviride treated pepper seedlings +

PO- Pathogen Only 
In Vitro and Enzymatic Studies of Inhibitory Activities of Three Trichoderma Species against Pythium Aphanidermatum in Infected Sweet Pepper
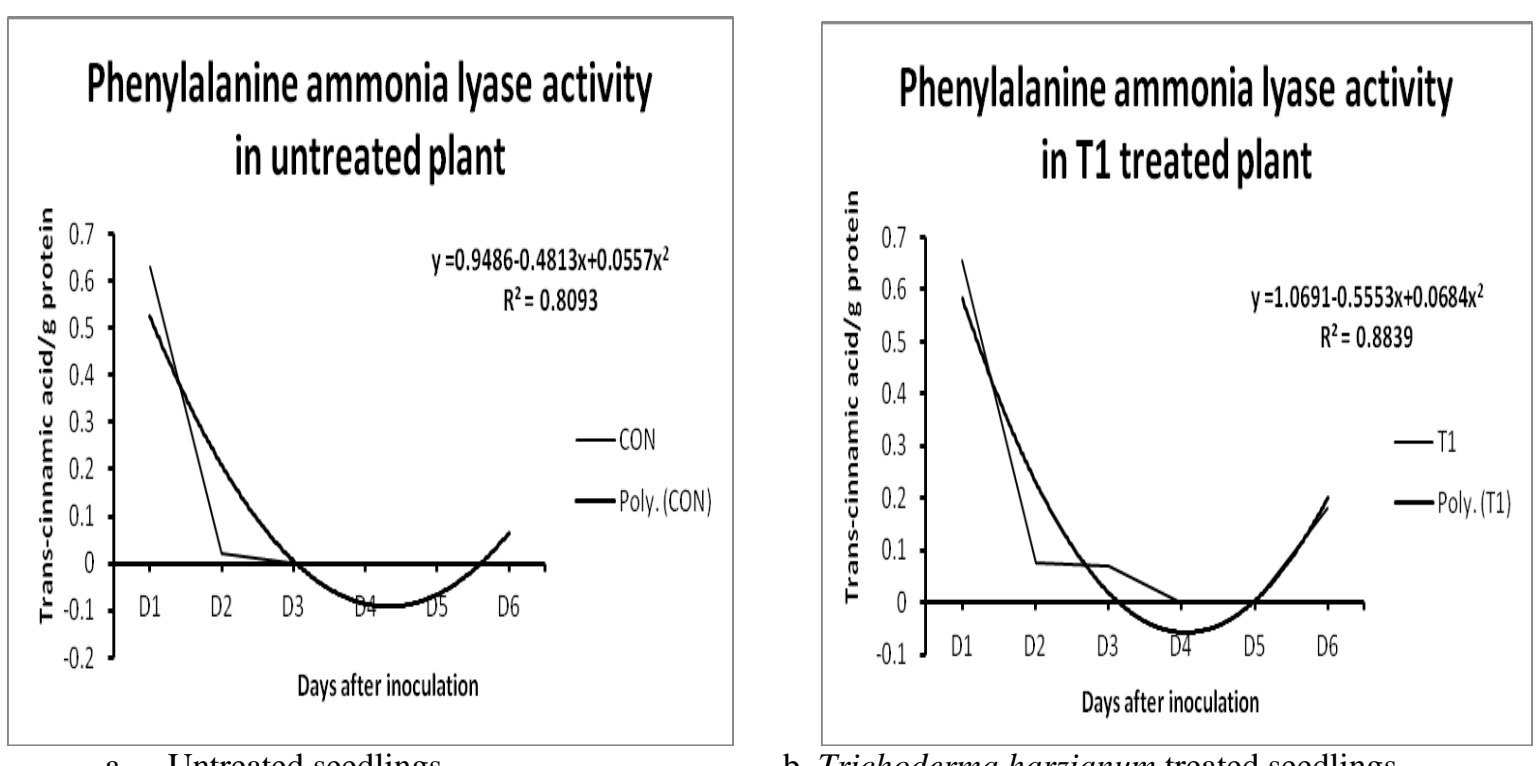

a. Untreated seedlings

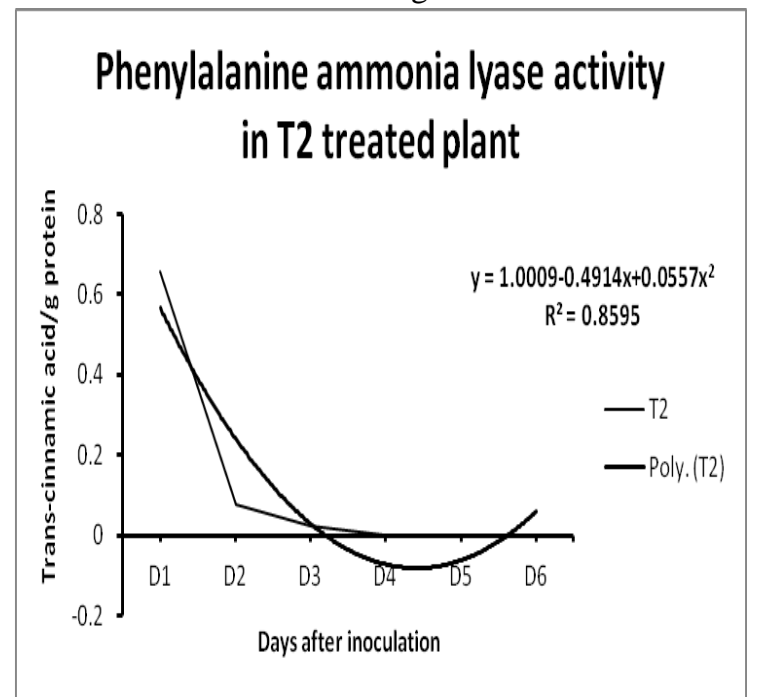

b. Trichoderma harzianum treated seedlings

c. Trichoderma koningii treated seedlings

d. Trichoderma atroviride treated seedlings

Figure 5: Changes in phenylalanine ammonia lyase activities of Trichoderma treated pepper (b-d) and untreated pepper (a) seedlings across the days of assay. 
In Vitro and Enzymatic Studies of Inhibitory Activities of Three Trichoderma Species against Pythium Aphanidermatum in Infected Sweet Pepper

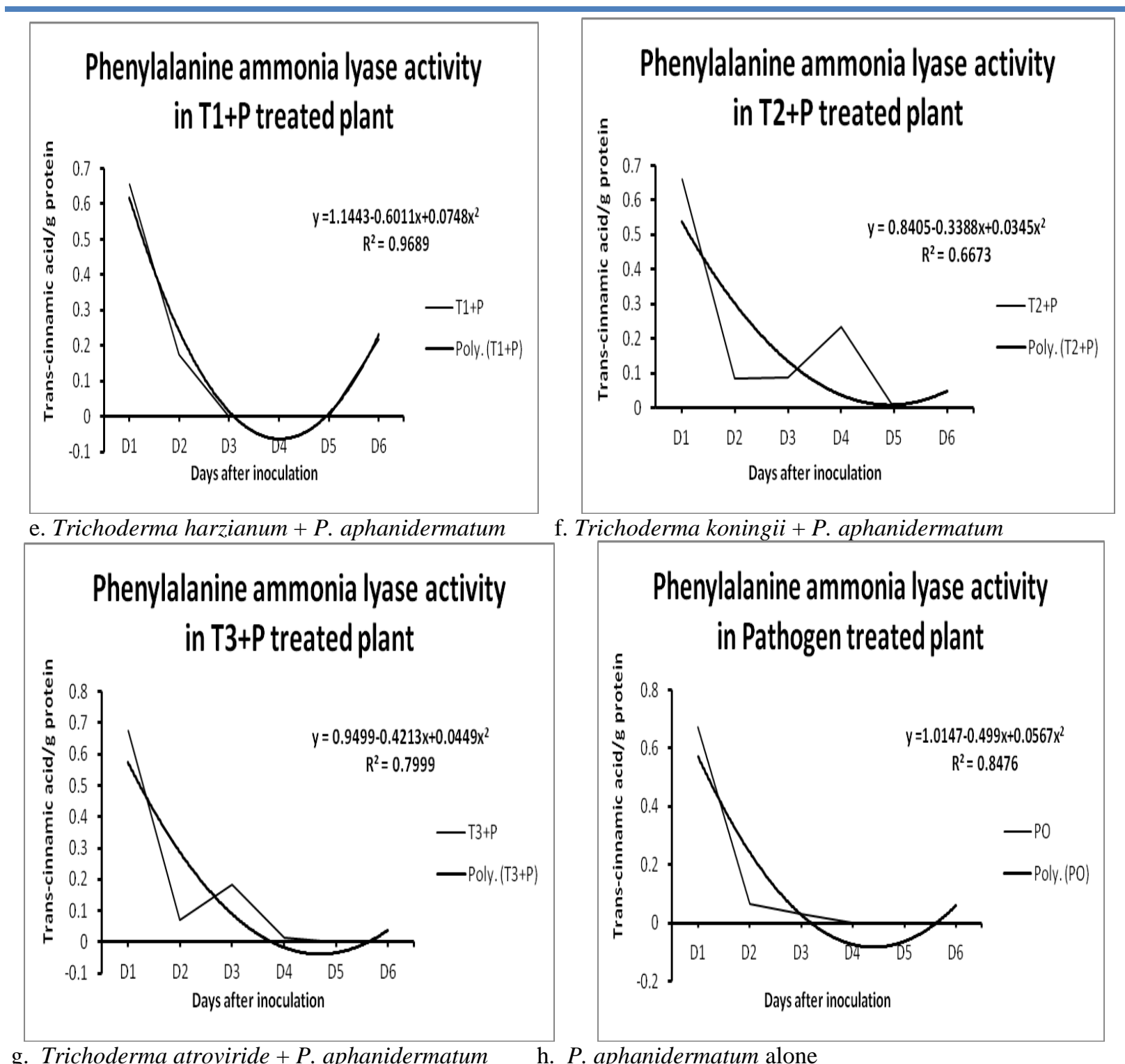

Figure 6: Changes in phenylalanine ammonia lyase activities of Trichoderma treated (e-g) pepper and untreated pepper (h) seedlings inoculated by Pythium aphanidermatum across the days of assay. 
In Vitro and Enzymatic Studies of Inhibitory Activities of Three Trichoderma Species against Pythium Aphanidermatum in Infected Sweet Pepper

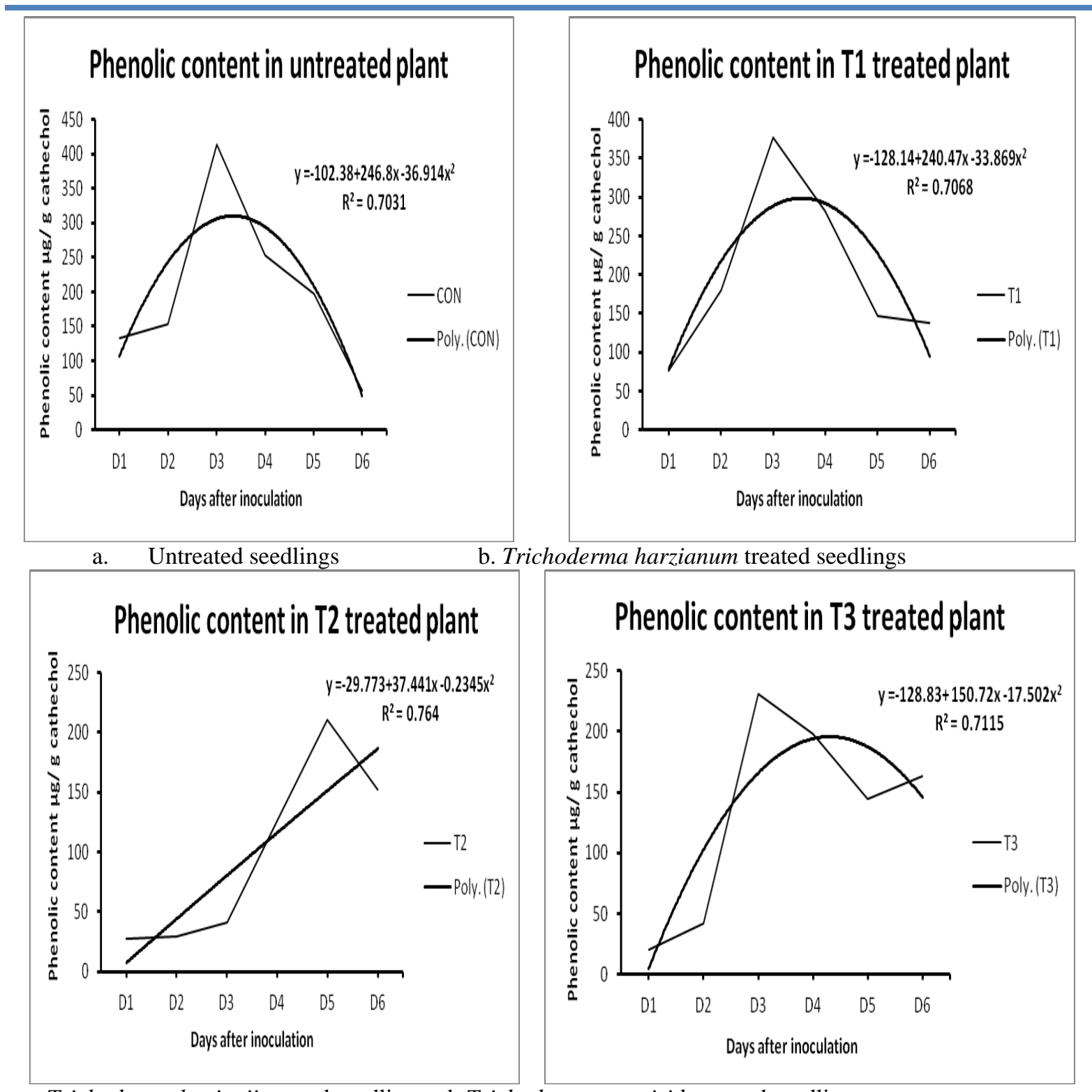

c. Trichoderma koningii treated seedlings d. Trichoderma atroviride treated seedlings

Figure 7: Changes in phenolic contents of Trichoderma treated pepper (b-d) and untreated pepper (a) seedlings across the days of assay. 
In Vitro and Enzymatic Studies of Inhibitory Activities of Three Trichoderma Species against Pythium Aphanidermatum in Infected Sweet Pepper
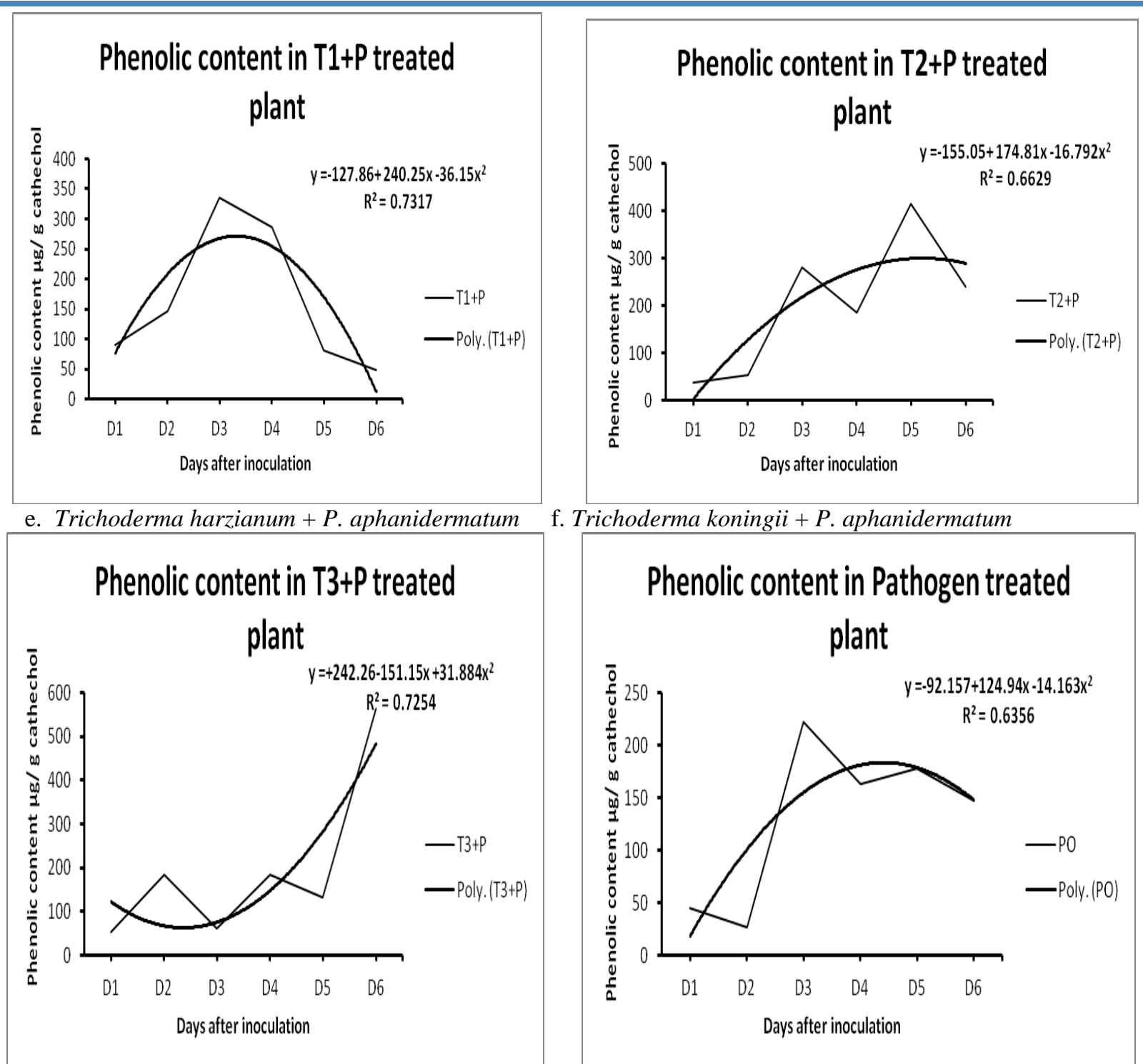

f. Trichoderma koningii $+P$. aphanidermatum

g. Trichoderma atroviride $+P$. aphanidermatum

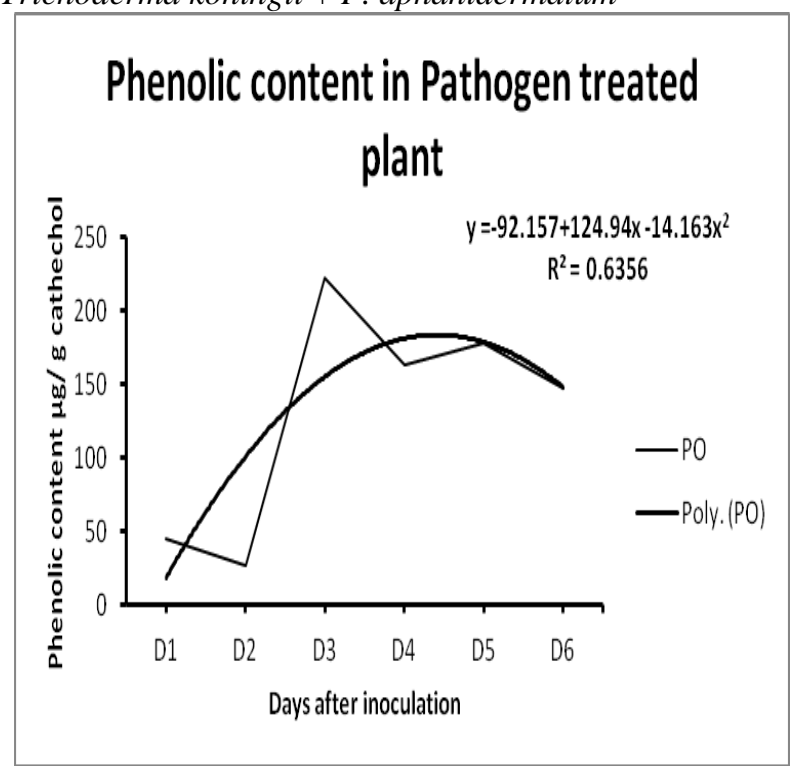

Figure 8: Changes in phenolic contents of Trichoderma treated (e-g) pepper and untreated pepper (h) seedlings inoculated by Pythium aphanidermatum across the days of assay

Generally, peaks of peroxidase activities in dual inoculations of each of the three Trichoderma species with $P$. aphanidermatum were $140-220 \%$ higher than in the control plant, this could be due interactive responses triggered in pepper plant to pathogenic infection, which was reflection of incompatible reactions between the antagonists and pathogen in the plant. In fact, Vidhyasekaran (1997) reviewed that the peroxidase activity was more in the plants with infection by the pathogens and it plays an important role in inhibiting pathogen development. The peak level of peroxidase activity observed in T. atroviride treated seedlings plus $P$. aphanidermatum $(0.8 \Delta$ $\mathrm{O} . \mathrm{D} / \mathrm{min} / \mathrm{g}$ protein) was about $120 \%$ higher than in singular inoculation of $T$. atroviride $(0.35 \Delta$ O.D $/ \mathrm{min} / \mathrm{g}$ protein), $100 \%$ higher than in $T$. harzianum (0.4A O.D/min/g protein) and $160 \%$ higher than in pathogen alone $(0.3 \Delta$ O.D $/ \mathrm{min} / \mathrm{g}$ protein) for the days of interactions, this suggested that, infection could be implicated to cause increase in the production of this enzyme, but only stimulated in plant treated with Trichoderma species, especially T. atroviride. Therefore it was observed that, increase in peroxidase activities quantitatively was triggered by biochemical responses in sweet pepper seedlings as stimulated by Trichoderma species to penetration and colonization of Pythium aphanidermatum, which could be as a result of metabolic demand at infection 
In Vitro and Enzymatic Studies of Inhibitory Activities of Three Trichoderma Species against Pythium Aphanidermatum in Infected Sweet Pepper

site (Salami, 1998). Interestingly, peroxidase activity in treated sweet pepper plant extracts was higher than that of the control in the absence of $P$. aphanidermatum infection. These results conform with the previous study by Van Wees et al. (2008), illustrated that defence responses in primed plants are not activated directly but are accelerated upon attack by pathogens or insects, resulting in faster and stronger resistance to the invading pathogens.

The activity of polyphenol oxidase was sustained at higher level for a longer period in dual inoculation of $T$. koningii plus $P$. aphanidermatum changing at the rates of $\pm 4 \%$ than when compared with singular inoculation of $T$. koningii and $T$. atroviride which decreased at the rate of $5-36 \%$. This implies that, the defense activity of this enzyme was prolonged to regulate infection process in host plant as induced by Trichoderma koningii in the presence of pathogen. Plants immediately respond to pathogens attack by a rise in PPO content, indicating immediate synthesis of antimicrobials to ward off pathogen. In elicitor treated plant, PPO activity increases slowly day by day suggesting that plant has got stimuli to increase PPO quantity or increased in the synthesis of the substrate progressively. Increase in PPO activity was reported by Nawrocka et al. (2011) where a gradual increase in polyphenol content was observed when treated with Trichoderma isolates. Marked increase in PPO activity was observed in banana roots treated with Psuedomonas fluorescens against Fusarium wilt (Thangavelu et al., 2004).

Peroxidase and polyphenol oxidase are important in the defence mechanism against pathogens, through their role in the oxidation of phenolic compounds to quinines, causing increasing in antimicrobial activity. Therefore, they may be directly involved in stopping pathogen development (Quiroga et al., 2000; Melo et al.,2006). Similarly, systemic resistance was enhanced in response to $R$. solanacearum inoculated tomato due to high accumulation of defense enzymes in Trichoderma treated seedlings (Vanitha et al., 2009). However, as both peroxidase and polyphenol oxidase increases there was significant reduction in the activity of phenylalanine ammonia lyase, suggesting competition between these two enzymes and PAL or both PER and PPO suppresses the activity of PAL. Additionally, activity of PAL seems to deplete the amount of total phenols accumulated or metabolized phenolic contents in the cells of pepper seedlings as the days of assay progresses.

\section{References}

1) Abo-Elyousr, K.A.M., Hashem, M., and Ali, E.H. (2009). Integrated control of cotton root rot disease by mixing fungal biocontrol agents and resistance inducers. Crop Protection, 28: $295-301$

2) Ajith, P. S. and Lakshmidevi, N. (2010). Effect of volatile and non-volatile compounds from Trichoderma spp. against Colletotrichum capsici incitant of anthracnose on bell pepper. Nature and Science, 8 (9):265-269.

3) Avdiushko, S.A., Ye ,X. S. and Kuć, J. (1993). Detection of several enzymatic activities in leaf prints cucumber plant. Physiological and Molecular Plant Pathology. 42: 441-454.

4) Brunner, K., Peterbauer, C. K., Mach, R. L., Lorito, M., Zeilinger, S. and Kubicek, C.P. (2003). The Nacetylglucosaminidase of Trichoderma atroviride is essential for chitinase induction by chitin of and major relevance to bio-control. Current Opinion in. Genetics. 43: 289-295.

5) Chittoor, J. M., Leach, J. E. and White, F. F. (1997). Differential induction of a peroxidase gene family during infection of rice by Xanthomonas oryzae pv. oryzae. Molecular Plant to Microbe Interactions. 10: 861 to 871.

6) Das, K. K., Panda, D., Nagaraju, M., Sharma, S. G. and Sarkar, R. K. (2004). Antioxidant enzymes and aldehyde releasing capacity of rice cultivars (Oryzae sativa $L$.) and determinants of anaerobic seedling establishment capacity. Bulgarian Journal Plant Physiology. 30:34-44.

7) Doka, O., Bicanic, D. D., Dicko, M. H. and Slingerland, M. A. (2004). Photoacoustic approach to direct determination of the total phenolic content in red sorghum flours. Journal of Agricultural Food Chemistry. 52: 2133-2136.

8) Goyal, S. P., Jandaik, C. L. and Sharma, V. P. (1994). Effect of weed fungi metabolites on the mycelial growth of Agaricus bisporus (Lang) Imbach. Mushroom Research. 3: 69-74.

9) Hammerschmidt, R. (1999). Phytoalexins: what have we learned after 60 years? Annual Reviews of Phytopathology 37: $285-306$

10) Hammerschmidt, R. (2005). Phenols and plant pathogen interactions: The saga continues. Physiological and Molecular Plant Pathology. 66: 77-78.

11) Harman, G. E., Howell, C. R., Viterbo, A., Chet, I. and Lorito, M. (2004). Trichoderma species opportunistic, avirulent plant symbionts. Nature Reviews Microbiology., 2:43-56.

12) Harman, G.E., (2006). Overview of mechanisms and uses of Trichoderma spp. Phytopathology, 96: 190-194.

13) Hiraga, S., Sasaki, K., Ito, H., Ohashi, Y. and Matsui, H. (2001).A large family of class III plant peroxidases. Plant and Cell Physiology42: 462-468.

14) Kerkeni, A., Daami-Remadi, M., Tarchhoun ,N. and Khedher, B.N. (2007) In vitro and in vivo suppression of Fusarium oxysporium f.sp. radicis-lycopersici the causal agent of Fusarium crown and root rot of tomato by some compost fungi. International Journal of Agricultural Research. 2, 111-115.

15) Kullnig, C., Mach, R.L., Lorito, M., and Kubicek, C. P. (2000). Enzyme diffusion from Trichoderma atroviride (T. Harzianum P1) to Rhizoctonia solani is a prerequisite for triggering of Trichoderma ech42gene expression before mycoparasitic contact. Applied Environmental Microbiology, 66: 2232-2234.

16) Li, L. and Steffens, J. C. (2002). Over expression of polyphenol oxidase in transgenic tomato plants results in enhanced bacterial disease resistance. Planta 215:239-247.

17) Melo, G.A., Shimizu, M.M., and Mazzafera, M. (2006). Polyphenol oxidase activity in coffee leaves and its role in resistance against the coffee leaf miner and coffee leaf rust. Phytochemistry., 67:277-285. 
In Vitro and Enzymatic Studies of Inhibitory Activities of Three Trichoderma Species against Pythium Aphanidermatum in Infected Sweet Pepper

18) Mishra, V. K. (2010). In vitro antagonism of Trichoderma species against Pythium aphanidermatum. Journal of Phytology, 2(9): 28-35. www.journal-phytology.com.

19) Morsy, M., Ebtsam, K. A., Abdel-Kawi, Khalil, M. N. A. (2009). Efficiency of Trichoderma viride and Bacillus subtilis as bio-control agents against Fusarium solani on tomato plants. Egyptian Journal of Phytopathology. 37:4757.

20) Narasimha Murthy, K., Nirmala Devi, D., and Srinivas, C. (2013). Efficacy of Trichoderma asperellum against Ralstonia solanacearum under greenhouse conditions. Annuals of Plant Sciences. 02 (09):342-350.

21) Nawrocka, J., Snochowska, M., Gajewska, E., Pietrowska, E., Szczech, M., and Małolepsza, U. (2011). Activation of defense responses in cucumber and tomato plants by selected polish Trichoderma strains. Vegetable Crops Research Bulletin. 75:105-116.

22) Nicholson, R.L. and Hammerschmidt, R. (1992) Phenolic compound and their role in disease resistance. Annual Reviews of Phytopathology. 30:369-389

23) Padmodaya, B. and Reddy, H.R., (1996). Screening of Trichoderma spp. against Fusarium oxysporium f.sp. lypersici causing wilt in tomato. Indian Journal of Mycology and Plant Pathology 26,266-270.

24) Quiroga, M., Guerrero, C., Botella, M.A., Barcelo', A., Amaya, I., Medina, M.I., Alonso, F.J., de Forchetti, S.M. , Tigier, T. and Valpuesta, V. (2000). A tomato peroxidase involved in the synthesis of lignin and suberin, Plant Physiology. 122:1119-1128.

25) Reddy, K. J., Wang, L. and Gloss, S. P. (1995). Solubility and mobility of copper, zinc and lead in acidic environments. Plant and Soil. 171, 53-58.

26) Salami, A.O. (1998). Biochemical interactions of mycorrhiza and soil microorganisms on growth of pepper (Capsicum annum. Linn.) seedlings. Ph.D Thesis. Pp: 126-127.

27) Salami, A. O., Olawole, O. I. and Oni, A. C. (2011). Effect of interactions between Glomus mosseae and Pythium aphanidermatum on the growth performance of okra plant seedlings. Journal of Science Research. Nigeria.

28) Shashidhara, S., Lokesh, M.S., Lingaraju, S., Palakshappa, M.G. (2008). In vitro evaluation of microbial antagonists, botanicals and fungicides against Phyptophthora capsici Leon. The causal agent of foot rot of black pepper. Karnataka Journal of Agricultural Sciences 21, 527-531

29) Stevens, L. H., Davelaar, E., Kolb, R. M., Pennings, E. J. M. and Smit, N. P. M. (1998). Tyrosine and cysteine are substrates for black spot synthesis in potato. Phytochemistry 49:703-707

30) Svetlana, Z., Stojanovic, S., Ivanovic, Z., Gavrilovic, V. Tatjana, P. and Jelica-balaz. (2010). Screening of antagonistic activity of microorganisms against Colletotrichum acutatum and Colletotrichum gloeosporioides, Archives of Biological Science., Belgrade, 62(3), pp611-623.

31) Thangavelu, R. A., Palaniswami, B. and Velazhahan, R. (2004). Mass production of Trichoderma harzianum for managing Fusarium wilt of banana. Agriculture Ecosystem Environment, Vol. 103, pp. 259-263.

32) Thomashow, S.L. (1996). Biological control of plant root pathogens. Current Opinion in Biotechnology. 7: 343-347.

33) Van Wees, S.C.M., van der Ent, S., and Pieterse, C.M.J. (2008). Plant immune responses triggered by beneficial microbes. Current Opinion in Plant Biology. 11: 443-448.

34) Vanitha, S. C., Niranjana, S. R. and Umesha, S. (2009). Role of phenylalanine ammonia lyase and polyphenol oxidase in host resistance to bacterial wilt of Tomato. Journal of Phytopathology. 157: 552-557.
35) Verma M., Brar S.K., Tyagi R.D., Surampalli R.Y. and Valero J.R.(2007). Antagonistic fungi, Trichoderma spp.: panoply of biological control. Biochemical Engineering Journal. 37, 1-20.

36) Watanabe, T. (2002). Pictorial Atlas of Soil and Seed Fungi: Morphologies of Cultured Fungi and Key to species. 2nd Edn. CRC Press.

37) Yedidia, I., Benhamou, N., and Chet, I. (1999). Induction of defense responses in cucumber plants (Cucumis sativus L.) by the biocontrol agent Trichoderma harzianum. Applied Environmental Microbiology. 65: 1061-1070.

38) Zieslin, N. and Ben-Zaken, R. (1993). Peroxidase activity and presence of phenolic substances in peduncles of rose flowers. Plant Physiology and Biochemistry. 31:333-339. 